\title{
La violencia contra trabajadores de la salud
}

\author{
Violence against health workers
}

\author{
A. Porfirio Cervantes-Pérez* \\ Académico Emérito, Expresidente de la Academia Mexicana de Cirugía, México
}

El aumento de la violencia que se ejerce en contra de los profesionales de la salud es motivo de creciente alarma. Su frecuencia y formas de presentación son variables según los diferentes países y los diversos ámbitos de trabajo del profesional de la salud, pero sus consecuencias son las mismas: muerte, lesiones físicas o mentales, incapacidad, ausentismo, cierre de instituciones de salud, disminución de la productividad y de la calidad de la atención médica, o franca limitación del acceso a los servicios de salud, lo que conforma un verdadero problema de salud pública.

Se distinguen tres posibles escenarios del problema de acuerdo con el ámbito de actividad profesional del trabajador de la salud: los países o regiones que sufren conflictos bélicos en curso; los países o áreas que gozan de relativa paz y tranquilidad; y los países o regiones donde existen conflictos de baja intensidad o se vive la presencia del crimen organizado. En países o regiones que sufren conflictos bélicos, el Comité Internacional de la Cruz Roja registró entre enero de 2012 y diciembre de 2014 unos 2400 incidentes violentos en 11 países, y desde mayo de 2016 hasta 2018 más de 1200 incidentes de violencia contra instalaciones o miembros del personal de salud en 16 países en forma de amenazas, secuestros, homicidios, destrucción y cierre de instalaciones de salud, Ante esta situación, gracias al trabajo del Comité y de otras organizaciones internacionales se ha logrado una condena unánime de los hechos y la promulgación, el 3 de mayo de 2016, de la resolución 2286 del Consejo de Seguridad de la Organización de las Naciones Unidas (ONU) que aborda el problema de tales actos violentos y establece las medidas a tomar en estas zonas de conflicto'. Por su parte, en septiembre de 2015, la Organización Mundial de la Salud, al informar del asesinato de 654 trabajadores de la salud desde el inicio del conflicto en Siria, lamenta la situación en este país donde más de la mitad de los hospitales públicos y centros de salud están cerrados o funcionan parcialmente, al tiempo que la Asociación Médica Mundial, en su $67^{\mathrm{a}}$ Asamblea General en Taipei (Taiwán), en octubre de 2016, señala que desde 2011, cuando dio comienzo la guerra en Siria, 270 establecimientos de salud han sido atacados y 760 profesionales de la salud han sido asesinados, y exige que todos los países garanticen la seguridad del personal de salud en situaciones de conflicto e implementen la Resolución 2286 de la ONU para asegurar el respeto y la protección de estos profesionales no solo en situaciones de guerra, sino también en situaciones similares en el mundo.

En otro escenario, en un estudio sobre las agresiones al personal de salud en países latinoamericanos de habla hispana que no experimentan situaciones de guerra propiamente dichas, se refiere un $66.7 \%$ de incidentes violentos, de los cuales el $11.3 \%$ resultaron en lesiones físicas y el $73.4 \%$ ocurrieron en instituciones públicas, principalmente en el área de urgencias ${ }^{2}$. La causa más frecuente en estos casos fue la insatisfacción del usuario por demoras en la atención, falta de medicamentos y resultados no satisfactorios según las expectativas de los pacientes o de las familias, que responsabilizan al personal por los hechos. Los autores recomiendan medidas inmediatas de seguridad institucional, mejora de la atención de urgencias, asignación de mayores recursos y mejora en la formación del personal en cuanto a sus capacidades de comunicación con los usuarios de los servicios.

\footnotetext{
Correspondencia:

*Ángel Porfirio Cervantes-Pérez

Joaquín Mucel, 13-2

Col. Héroes de la Revolución

C.P. 53840, Naucalpan, México

E-mail: cervez@yahoo.com.mx
}

Fecha de recepción:17-05-2018

Fecha de aceptación: 23-05-2018

DOI: 10.24875/CIRU.M18000060
Cir Cir. 2018;86:473-474

Contents available at PubMed www.cirugiaycirujanos.com 
En el grupo de países o regiones que sufren conflictos de baja intensidad generados por conflictos sociales diversos, o que han visto crecer la criminalidad y los actos violentos de la delincuencia organizada, países entre los cuales habrá que considerar al nuestro, independientemente de las agresiones personales por insatisfacción habría que considerar otras situaciones particulares. De acuerdo con noticias de la prensa y datos de algunas asociaciones médicas, la violencia y los crímenes en el país en contra de médicos, enfermeras y residentes va en aumento. Entre 2013 y 2017 se registraron siete asesinatos de pasantes de medicina y residentes y 19 de médicos o enfermeros, 9 casos de agresiones físicas (desde golpes hasta intentos de asesinato), 2 desapariciones, 3 asaltos a centros de salud, 25 médicos asaltados y 71 profesionales amenazados. Las causas básicas son dos: carencias del sistema de salud que generan insatisfacción y actos violentos del crimen organizado. El personal de salud que labora principalmente en áreas aisladas o bajo control de la delincuencia puede verse amenazado y presionado para atender lesionados de los grupos criminales y rendir buenas cuentas, y las unidades médicas pueden verse asaltadas por diversos motivos. El trabajador de la salud en estas condiciones labora en un ambiente de alto riesgo y sensación permanente de inseguridad.

El problema de la violencia en contra de los trabajadores de la salud es real y con perspectivas de crecimiento, e involucra a la sociedad, al Estado en su conjunto y en particular a las instituciones de salud, a las instituciones académicas y a las organizaciones médicas. Por consiguiente, es indispensable abordar el problema de forma integral y participativa, combinando medidas de prevención que vayan a las raíces de la violencia y medidas inmediatas para mitigar los daños. El Comité Internacional de la Cruz Roja, en un documento publicado en 2016, señala recomendaciones generales aplicables en situaciones del asunto que nos ocupa, no solo en condiciones de conflicto bélico, sino en cualquier otro lugar y circunstancia ${ }^{3}$; entre ellas, la necesidad de cambios en la legislación interna de cada país que contemplen la protección específica y estímulos al personal de salud que labora en áreas de alto riesgo, la capacitación del personal para una mejor integración con la comunidad y para el manejo de situaciones críticas, medidas de protección de las unidades médicas en zonas de riesgo y la participación comprometida de la sociedad. Sobre estas bases, el tema debería ser motivo de reflexión, análisis y discusión en los niveles académicos.

\section{Bibliografía}

1. Comité Internacional de la Cruz Roja (CICR). Cada semana se cometen ataques contra trabajadores de la salud. Comunicado de prensa, 3 de mayo de 2018. (Consultado el 21/5/2018.) Disponible en: http/www.icr.org/ es/document/cicr-cada-semana-se-cometen-ataques-contra-trabajadores-de-la-salud

2. Travetto $C$, Daciuck D, Fernández S, Ortiz P, Mastandueno R, Prats $M$, et al. Agresiones hacia profesionales en el ámbito de la salud. Rev Panam Salud Publica. 2015;38:307-13.

3. Comité Internacional de la Cruz Roja (CICR). Proteger la asistencia a la salud. Recomendaciones básicas. Noviembre 2016. (Consultado el 22/5/2018.) Disponible en: http/www/icr.org/es/publication/proteger-la-asistencia-de-salud-recomendaciones-básicas 